\title{
LA GUERRA SALVADOREÑA VISTA DESDE LA LITERATURA AUTOFICCIONAL: DIOS TENÍA MIEDO, DE VANESSA NÚÑEZ HANDAL
}

\author{
Valeria Grinberg Pla*
}

\begin{abstract}
Resumen: Este artículo analiza el trabajo de memoria de la novela Dios tenía miedo, de Vanessa Núñez Handal. Al indagar en el pasado familiar y nacional salvadoreño por medio de una exploración autoficcional de los modos en los cuales su familia estuvo involucrada en la guerra que ella misma vivió siendo niña, Vanessa Núñez Handal experimenta con el potencial explicativo de la imaginación creativa y el lenguaje simbólico, en un proceso en el cual escribir parece ser tanto método como objetivo a fin de recordar y, sobre todo, comprender el percepticidio que tuvo lugar durante la guerra. La ambigüedad del pacto autoficcional que rige la novela le da la libertad de combinar técnicas ficcionales, autobiográficas y testimoniales, a efectos de articular su interpretación del pasado traumático.
\end{abstract}

Palabras clave: Vanesa Núñez Handal, literatura, infancia, memoria, autoficción, percepcticidio, guerra, El Salvador.

\begin{abstract}
This article analizes the labors of memory in Vanessa Núñez Handal's novel Dios tenía miedo. By looking into both the familial and the national past in El Salvador through an autofictional exploration of the ways in which her own family was involved in the war she herself experienced as a child, Vanessa Núnez Handal experiments with the explanatory potential of both the creative imagination and the use of symbolic language, in a process where writing seems to be as much a method as a goal in order to remember and, above all, understand the percepticide that took place during the war. The ambiguity of the autofictional pact rules over the novel, giving her the liberty to combine fictional, autobiographical, and testimonial techniques, with the aim of articulating her interpretation of the traumatic past.
\end{abstract}

Keywords: Vanesa Núñez Handal, literature, childhood, memory, autofiction, percepticide, war, El Salvador.

Fecha de recepción: 13/10/2015 - Fecha de aceptación: 10/02/2016

* Argentina. Doctora en Letras por la Universidad Johann Wolfgang Goethe de Frankfurt, Alemania. Actualmente es profesora asociada de literatura y estudios culturaltes latinoamericanos en Bowling Green State University, Ohio, EE. UU. Correo electrónico: vgrinb@bgsu.edu 
"Yo, que no sabía siquiera que existiera el museo, fui más por morbo que porque me interesaran los hechos.

No me atreví a firmar el libro de visitas con mi nombre, y escribí uno inventado. Uno que me permitiera mirar sin dejar evidencia de mi atestiguamiento".

Vanesa Núñez Handal,

Dios tenía miedo

$\mathrm{E}$

$n$ este trabajo me interesa discutir el trabajo de memoria que tiene lugar en la novela Dios tenía miedo de la escritora salvadoreña Vanessa Núñez Handal. ${ }^{1} \mathrm{Al}$ indagar en el pasado familiar y nacional salvadoreño por medio de una exploración autoficcional de los modos en los cuales su familia estuvo involucrada en la guerra que ella misma vivió siendo niña, esta novela constituye una innovación en el campo de las representaciones literarias de la guerra en El Salvador, entre las que se encuentran las ficciones de Horacio Castellanos Moya, Jacinta Escudos, Rafael Menjívar Ochoa y Claudia Hernández, para nombrar tan solo a parte de las escritoras y escritores más representativos. ${ }^{2}$

Entiendo que la decisión de Vanessa Núñez Handal de hacer memoria y explorar cuestiones relacionadas con la propia identidad y el significado del pasado reciente a través de la escritura autoficcional implica un concepto de memoria que no corresponde a la noción referencial de la verdad. En su lugar, la autora experimenta con el potencial explicativo de la imaginación creativa y el lenguaje simbólico, en un proceso en el cual escribir parece ser tanto método como objetivo a fin de recordar y, sobre todo, comprender y, en el cual, la ambigüedad característica del pacto autoficcional -a caballo entre la documentación y la ficción- es terreno fértil para el trabajo de memoria de la novela.

Podemos leer Dios tenía miedo como una autoficción, ya que se trata de una historia inventada a partir de las experiencias de vida de la autora y su entorno familiar, en la cual es posible identificar claramente a la narradora y protagonista, Natalia, con Vanessa Núñez Handal, pese a que no haya una coincidencia de nombre propio entre estas mismas. Como explica Manuel Alberca:

1 Vanessa Núñez Handal, Dios tenía miedo (Guatemala, Guatemala: F\&G Editores, 2011).

2 A estas alturas es indiscutible la importancia de la narrativa como herramienta y espacio para el trabajo de memoria en situaciones de posguerra o posdictadura. Para una discusión de literatura y memoria en Centroamérica, véase Werner Mackenbach, "Narrativas de la memoria en Centroamérica: Entre política, historia y ficción", en: (Per)Versiones de la modernidad. Literaturas, identidades, desplazamientos, (eds.) Beatriz Cortez, Alexandra Ortiz Wallner y Verónica Ríos Quesada (Guatemala, Guatemala: F\&G Editores, 2012), 231-257, esp. 244-249. 
La guerra salvadoreña vista desde la literatura autoficcional: Dios tenía miedo, de Vanessa Núñez Handal

“[...] la autoficción supone la capacidad de inventar una historia a partir de la vida y las fantasías de uno mismo y aprovechar las de los otros para construir una aventura propia. Por tanto, la autoficción no es una novela autobiográfica más, sino una propuesta ficticia y/autobiográfica con tanta transparencia y claridad que el lector puede sospechar que se trata de una pseudo-novela o una pseudo-autobiografía. [...] Su transparencia autobiográfica proviene de la identidad nominal, explícita o implícita, del narrador y/o protagonista con el autor de la obra, cuya firma preside la portada". ${ }^{3}$

Sin embargo, Dios tenía miedo no propone una coincidencia nominal entre la narradora y la autora, por lo que se mueve precisamente en el terreno ambiguo de la sospecha, del cual se nutre la construcción de la memoria y su propuesta de verdad. En lugar de la certeza del nombre -que aludiría también a la certeza sobre el significado de un pasado en disputa y permanente reinterpretación-, hay un guiño con respecto al uso de nombres falsos en la novela, como puede comprobarse en el epígrafe que precede este trabajo. ${ }^{4}$ El motivo por el cual, para entender cabalmente la propuesta de Núñez Handal en Dios tenía miedo, es importante leerla como autoficción -y no como novela autobiográfica- a pesar de la falta de identidad nominal entre autora y narradora/protagonista reside en que esta obra tiene un pacto de lectura ambiguo que apela tanto al código novelesco como al autobiográfico y -como se verá más adelante- al testimonial.

En el presente artículo propongo, por tanto, que Vanessa Núñez Handal, como otros autores o autoras de la llamada segunda generación que utilizan la escritura creativa o el cine como herramientas de memoria, se sitúa precisamente a medio camino entre un paradigma documental y un paradigma constructivista en lo que respecta a su aproximación al pasado o, mejor dicho, a la producción de conocimiento sobre el pasado $y$, a tal efecto, se vale de las posibilidades de la autoficción. ${ }^{5}$ Paso a explicar esta importante diferencia, la cual permite entender la eficacia de la autoficción como género desde el cual dar sentido a los hechos de un pasado traumático, como el de la guerra en El Salvador. Desde un paradigma documental, se entiende que la verdad de un enunciado depende de su validación por medio de registros independientes de la persona que lo emite, tales como entrevistas, reportajes, diarios, discursos públicos, etc. De este modo,

3 Manuel Alberca, El pacto ambiguo. De la novela autobiográfica a la autoficción (Madrid, España: Editorial Biblioteca Nueva, 2007), 128.

4 Por cierto, el mismo Manuel Alberca señala que la excepción a la regla de la identidad nominal "pone en entredicho el protocolo nominal" de la autoficción. Véase: Manuel Alberca, "El pacto ambiguo ("Bonus Track')", Ínsula (España) 754 (2009): 15.

5 Estoy pensando en autores y autoras como Laura Alcoba -Manèges: petite histoire argentine, 2007-, Patricio Pron -El espiritu de mis padres sigue subiendo en la lluvia, 2011-, Alejandro Zambra-Formas de volver a casa, 2011-, y en cineastas como Óscar Torres -guionista de Voces inocentes, 2004- y Laura Astorga -directora y guionista de Princesas rojas, 2013-. 
el paradigma documental basa su verdad en la autoridad del archivo, más allá del sujeto que la enuncia. Por el contrario, desde un paradigma constructivista, como su nombre lo indica, se asume que la verdad de un enunciado es el resultado de un ejercicio consciente y voluntario de creación y construcción de los principios que permiten establecer qué es verdad y qué no lo es. En el contexto de la filosofía política, la posición constructivista propone que somos los seres humanos quienes, por medio de una reflexión basada en principios compartidos, establecemos los hechos y personas que consideramos significativos para establecer lo verdadero. Así,

\begin{abstract}
"[...] el constructivismo revierte la visión común de la "verdad" como un juicio certero sobre un "hecho" cualquiera que existe independientemente de nosotros haciendo juicios políticamente "verdaderos", y que los "hechos" a los cuales se refieren dependen de que primero nosotros hayamos construido, por medio de la razón práctica, principios objetivamente válidos". 6
\end{abstract}

Propongo, entonces, que para entender cabalmente la verdad sobre la guerra en El Salvador, articulada en Dios tenía miedo, es necesario comprender las implicaciones filosóficas derivadas de su ímpetu documental y de su ímpetu constructivista, porque su verdad se desprende de la particular combinación de ficción -es decir, creación y documentación-, que constituye la autoficción de la novela. Esta ambigüedad e hibridez, resultado de que los pactos de lectura de la autobiografía y la novela, en lugar de funcionar de manera excluyente, operan de manera combinada, presentan un desafío para los lectores, ya que dificultan la fácil clasificación de la verdad del texto como objetiva o subjetiva, documental o ficcional. ${ }^{7}$ También Julia Negrete apunta que atribuir la clave de la autoficción a su pacto ambiguo "invita a hacer una lectura simultánea de dos géneros y establecer dos pactos, el autobiográfico y el novelesco, con lo que se ostenta lo contradictorio y paradójico, de esta forma de escritura". ${ }^{8}$ Pero, si Núñez Handal se sirve de la autoficción para articular su relato sobre la guerra, es porque entiende la ambigüedad no como contradicción o paradoja, sino como oportunidad para proponer una versión ficcional del pasado que no corta sus lazos con la realidad extraliteraria a la que remite, construyendo esta relación de manera compleja e híbrida.

Precisamente, y como se verá, Dios tenía miedo no establece una oposición binaria entre objeto y sujeto del conocimiento basada en la asunción de que

6 Michael Buckley, “Constructivism”, en: Encyclopedia of Global Justice (Nueva York, EE. UU.: Springer, 2011), 188. La traducción es mía.

7 Véase, a este respecto: Ana Casas, "El simulacro del yo: La autoficción en la narrativa actual", en: $L a$ autoficción: Reflexiones teóricas, (ed.) Ana Casas (Madrid, España: Editorial Arcos, 2012), 9-42.

8 Julia Negrete, "Tradición autobiográfica y autoficción en la literatura hispanoamericana contemporánea", De Raiz Diversa (México) 2-3 (2015): 231. 
La guerra salvadoreña vista desde la literatura autoficcional: Dios tenía miedo, de Vanessa Núñez Handal

objetividad es sinónimo de objetivismo, por lo cual su protagonista se involucra en la construcción de la memoria, del mismo modo que la autora se refleja ambiguamente en la narradora. Y en la medida en que la narradora/protagonista construya un sentido sobre el trauma de la guerra, también podrá (re)conocerse a sí misma. En consecuencia, la novela afirma la capacidad, y la necesidad, de comprender el pasado como condición de la identidad y apuesta por la hibridez de la autoficción como espacio desde el cual construir ese relato. A partir de una exploración de las dinámicas del yo como sujeto y objeto de la escritura autoficcional, Vanessa Núñez Handal transforma el objeto de la memoria, es decir, el pasado traumático, en el sujeto de la literatura creativa.

\section{El percepticidio de la guerra}

Publicada por la editorial F\&G en Guatemala, lugar de residencia actual de la autora, Dios tenía miedo interviene en el debate en curso sobre el significado del pasado reciente en El Salvador, específicamente, la memoria traumática de la guerra que tuvo lugar entre 1980 y $1992 .{ }^{9}$

"Estos son mis recuerdos". ${ }^{10}$ Con esta afirmación de la narradora comienza la novela, pero muy pronto la perspectiva de la primera persona es interceptada por las voces de otros en la forma de testimonios, diálogos, fragmentos de artículos periodísticos, discursos políticos y graffitis. En otras palabras, Dios tenía miedo es una novela-collage. Algunas de las perspectivas incorporadas son ficticias -como por ejemplo los testimonios incluidos-, otras, en cambio, son de carácter documental: intertextos de la época, tales como los eslóganes políticos de izquierda y de derecha o las noticias y crónicas periodísticas sobre la guerra. Lo importante es que todas las voces incluidas en el texto, sean ficcionales o documentales, interactúan bajo el paraguas literario de la novela, es decir, bajo el pacto de lectura de la (auto)ficción. Esto es evidente no solo en el hecho de que el libro haya sido publicado como tal, sino que es enfatizado, además, por medio del epígrafe que encabeza la novela, un poema de Julio Cortázar. No obstante, se trata de un tipo particular de novela, ya que su frase inicial anteriormente citada -"Estos son mis recuerdos"- así como la equívoca identificación autora-narradora a la que ya me he referido nos invitan a leerla como una memoria autoficcional.

9 Otras novelas publicadas en la última década que retratan la violencia de la guerra salvadoreña son El perro en la niebla (Bilbao, España: Verbigracia, 2006) de Róger Lindo, La sirvienta y el luchador (Barcelona, España: Tusquets Editores, 2011) y El sueño del retorno (Barcelona, España: Tusquets Editores, 2013) de Horacio Castellanos Moya, Camino de hormigas (La Libertad, España: Editorial Alfaguara, 2014) de Miguel Huezo Mixco y Noviembre (México, D.F.: Editorial Planeta, 2015) de Jorge Galán. A diferencia de Dios tenía miedo, donde la experiencia de los niños durante la guerra ocupa en lugar central -como en el ya mencionado film Voces inocentes de Luis Mandoki-, estas novelas se adentran en la guerra desde la perspectiva de personajes adultos -algunos de ellos muy jóvenes- involucrados en la guerra como víctimas o victimarios, guerrilleros o verdugos.

10 Núñez Handal, 11. 
En el año 2009, diecisiete años después de la firma de los acuerdos de paz, Natalia, la narradora en primera persona y alter ego de la autora, vuelve a El Salvador al tiempo que retorna a la memoria de la guerra, de modo que el viaje de regreso al país natal es disparador y metáfora del viaje de regreso al pasado. ${ }^{11}$

El enfoque de la narradora a veces reproduce la perspectiva que tenía de niña y a veces adopta su perspectiva actual de mujer adulta tratando de entender sus experiencias traumáticas durante la guerra. Los pasajes escritos desde la perspectiva de una niña son los que le permiten interrogar la inexplicable violencia que la rodea desde una mirada cándida. En consecuencia, su relato reproduce el lenguaje y la percepción de una niña curiosa, cuyas preguntas sobre la guerra no obtienen ninguna respuesta, o bien respuestas insatisfactorias, de parte de sus mayores.

De manera notable, los pasajes narrados desde la perspectiva de su infancia dan cuenta de un esfuerzo consciente por parte de sus antecesores de impedir toda percepción de la guerra a través de los sentidos: vista, oído, olfato y tacto son reprimidos por medio de un percepticidio o anulación voluntaria de los sentidos, a fin de no ver los cuerpos de los muertos tirados por doquier en calles y terrenos baldíos; no oír las bombas, ni las sirenas, ni los gritos; no oler la carne en descomposición de los cadáveres; no tocar ni ser tocado de ningún modo por la violenta realidad que les rodea.

Recurro aquí a la noción de percepticidio de Diana Taylor, que se refiere fundamentalmente al sentido de la vista, expandiéndola para describir cómo Natalia recuerda los esfuerzos de su padre y madre por impedirle no solo ver, sino también percibir el horror de la guerra y sus efectos a través de cualquiera de los sentidos. ${ }^{12}$ Hay numerosos ejemplos de esta estrategia a lo largo de la novela, ${ }^{13}$ baste con discutir en detalle el más significativo de todos ellos:

11 El motivo del viaje, es decir el retorno literal al lugar de origen, como disparador de la memoria -o, en otras palabras, del viaje imaginario al pasado-, es fundamental también en otras novelas de la memoria en Centroamérica, notablemente en ConPasión absoluta (Guatemala, Guatemala: F\&G Editores, 2005) de Carol Zardetto y El corazón del silencio (San José, Costa Rica: Editorial Norma, 2004) de Tatiana Lobo. En este contexto es interesante señalar que la ya citada novela El sueño del retorno, de Horacio Castellanos Moya, habla, en cambio, del viaje de regreso como imposible o fallido.

12 En su estudio sobre la violencia y sus representaciones durante la dictadura militar en la Argentina (1976-1983), Diana Taylor explica porqué fue posible para las fuerzas militares y paramilitares del régimen secuestrar a miles de personas en plena calle a la vista de todo el mundo y simultáneamente negar la política estatal de desapariciones, destinada a controlar y a aterrar a toda la población. A su entender, el sistema impuso un percepctidio, es decir, forzó a la población a mirar hacia otra parte para no ver nada que pusiera en duda el discurso oficial de la dictadura, pese a ser forzada a verlo. En sus palabras: "Ver lo peligroso, ver aquello que no estaba expuesto para ser visto, ponía en riesgo a la población en una sociedad policial que controlaba la mirada. La mutualidad y reciprocidad de la mirada, que permite a las personas identificarse con otras personas, cedió su lugar a la mirada desautorizada. Forzada a funcionar bajo la mirada vigilante, la gente no se animaba a ser descubierta mirando, a ser vista pretendiendo no ver. Mejor cultivar una cuidadosa ceguera. Una red de miradas subrepticias, posicionaba y silenciaba a aquellos que no aprobaban al régimen o no se identificaban con el proyecto militar. Esas miradas hicieron añicos la comunidad. En lugar de afinidad, uno reconocía al 'enemigo' en lo cotidiano, la división fatal entre nosotros y, repentinamente, ellos. El triunfo de la atrocidad consistió en forzar a la gente a mirar hacia otro lado -un gesto que deshizo su sentido de cohesión personal y comunitaria-, incluso pese a parecer aislarlos de un entorno inestable. Los espectáculos de violencia dejaron a la población muda, sorda y ciega". Diana Taylor, Disappearing Acts. Spectacles of Gender and Nationalism in Argentina's "Dirty War" (Durham y Londres: Duke University Press, 1997), 122-123. Cursivas en el original. La traducción es mía.

13 Véase por ejemplo, Núñez Handal, 59, 72, 125, 132. 
La guerra salvadoreña vista desde la literatura autoficcional: Dios tenía miedo, de Vanessa Núñez Handal

“Aunque las bombas y los balazos se habían escuchado la mayor parte de la noche, papá pensó que se trataba de algo sin importancia. A la mañana siguiente, cuando me llevaba al colegio en su auto, decidió pasar por la avenida que quedaba paralela a la nuestra. Papá no tuvo tiempo de girar. Sólo alcanzó a decir que debía taparme los ojos. No logró identificar que aquello que colgaba de las copas de los árboles que bordeaban la ancha avenida de doble vía, eran pedazos de cuerpos. Y yo, sentada en el asiento trasero, no pude dejar de ver aquel horror, que fue mi primer enfrentamiento con los años de pavor que habríamos de vivir durante la década siguiente. Papá condujo hasta el colegio en silencio. Yo no me atrevía a preguntar si debía sentir pena por los muertos que la guardia, según escuché luego en la radio, recogió con palas y bolsas plásticas, a fin de evitar una hedentina en una de las principales calles de nuestra ciudad capital". ${ }^{14}$

Lo que hace tan interesante esta cita es el hecho de que muestra tanto el intento de anular la percepción como el fracaso de dicho intento, tal y como Diana Taylor plantea que funciona el mecanismo del perceptidio: "Ver sin poder ver, desempodera absolutamente. Pero ver, sin siquiera admitir que uno está viendo, hace que la violencia se vuelva aún más sobre uno mismo. El percepticidio ciega, mutila, mata a través de los sentidos". ${ }^{15}$

En efecto, el percepticidio va de la mano con una cultura del miedo y del silencio que incluye "hacer ruido" como otra de las estrategias utilizadas para silenciar los sonidos de la guerra. Como describe la narradora, los adultos a su alrededor rezan y chismorrean y diseminan informaciones falsas para encubrir lo que está ocurriendo en El Salvador a causa de la guerra. Así, su infancia y adolescencia transcurren en una tensión permanente entre su percepción, a pesar del percepticidio, de la violencia y la negación descarada de esta misma. Es importante aclarar que el impacto de la violencia afecta directamente a su familia, ya que su propio primo hermano terminará siendo uno de los desaparecidos, y -sin embargo- las personas adultas a su alrededor no pueden escapar al mandato del percepticidio, lo que demuestra la eficacia de este como estrategia de disciplina de la población por parte del Estado. La novela sugiere, por el contrario, que la mirada ingenua de la infancia, personificada en Natalia y también en su amiga Jimena, es menos pasible de ser manipulada. El contraste entre la perspectiva de Natalia y la adulta es más que evidente. Y es precisamente desde su ingenua curiosidad que la narradora puede interpelar el discurso que avala e impone el percepticidio de la guerra. Esto no debe sorprendernos, ya que, como señala Brigitte Adriaensen, "la ingenuidad es una herramienta clásica de la ironía, que permite subrayar sutilmente ciertos aspectos problemáticos de una sociedad, como ya

14 Ibid, 14. Las negritas son mías.

15 Taylor, 124. La traducción es mía. 
fue el caso del cándido de Voltaire". ${ }^{16}$ Así, en el contexto de Dios tenía miedo, la ingenuidad de Natalia tiene por objeto llamar la atención sobre el percepticidio de la guerra.

En efecto, a pesar del mandato paterno de no mirar ni escuchar el espectáculo de la guerra, sus olores y sonidos llegan a Natalia. Más aún, su percepción reprimida de la guerra reaparece en su presente, persiguiéndola en forma de pesadillas. Para entender este pasado que la acosa, precisamente porque el conocimiento cabal de lo sucedido le ha sido negado, la narradora regresa a los vestigios de experiencia inscriptos fragmentariamente en su memoria.

\section{De la autoficción como novela del yo a la autoficción testimonial}

Además de proveer una retrospectiva autoficcional de los años de la guerra en primera persona a través del personaje de Natalia, Dios tenía miedo es un espacio dialógico en el que es posible escuchar diferentes voces sobre lo ocurrido y su significado. Un total de ocho capítulos reproduce una serie de conversaciones ficcionales entre Natalia y su amiga de infancia, Jimena, quien se vio obligada a salir al exilio junto a sus padres durante la guerra. ${ }^{17}$ En estas conversaciones, Jimena comparte con su amiga la información que circulaba fuera de El Salvador sobre la violencia estatal durante la guerra, así como su propia experiencia familiar de huida y exilio, todo lo cual contribuye a promover el trabajo de memoria de Natalia.

Una perspectiva de la guerra diametralmente opuesta a la de Jimena es la que ofrece un torturador anónimo cuyo testimonio ficcional forma parte de los esfuerzos de la autora para presentar la violencia de la guerra desde el punto de vista de los militares y paramilitares involucrados en la represión. ${ }^{18}$

Lo mismo ocurre con cuatro capítulos dedicados a relatar las experiencias de un miembro sin nombre de los escuadrones de la muerte, cuyos motivos para involucrase activamente en la guerra son expuestos en detalle por un narrador omnisciente a lo largo de cuatro capítulos, en los que podemos adentrarnos en el mundo interior de este personaje. ${ }^{19}$ Así, sus pensamientos ofrecen justificaciones del uso de la violencia por parte de grupos armados paramilitares fundamentadas, desde su lectura ideológica de la realidad social, en la necesidad de combatir el desorden imperante y, sobre todo, el avance del comunismo que amenaza su estilo de vida y estatus social de clase media acomodada:

16 Brigitte Adriaensen, "El exotismo de la violencia ironizado: Fiesta en la madriguera de Juan Pablo Villalobos", en: Narrativas del crimen América Latina: Transformaciones y transculturaciones del policial, (eds.) Brigitte Adriaensen y Valeria Grinberg Pla (Münster, Alemania: LIT Verlag, 2012), 162.

17 Véanse los capítulos 24, 27, 31, 36, 40, 53, 61 y 65.

18 Véase el capítulo 47.

19 Véanse los capítulos 8, 22, 30 y 45. 
La guerra salvadoreña vista desde la literatura autoficcional: Dios tenía miedo, de Vanessa Núñez Handal

"De conversaciones con amigos concluyó que, pese a la gravedad de la situación en El Salvador, no había autoridad a la cual acudir ni nada por hacer. El país, tal como él lo veía, se estaba viniendo abajo. Sintió miedo de perder todo aquello que, con trabajo y esfuerzo, había logrado desde su regreso. Pronto, aquel miedo que él jamás creyó posible sentir, se convirtió en odio. Odio que era compartido en sus círculos más cercanos. Sus excompañeros de colegio, sus amigos del club de tenis, su cuñado, sus suegros y demás personas ligadas al círculo empresarial.

Fue su cuñado quien le habló de un grupo organizado en La Escalón, compuesto por médicos, abogados y hasta oficiales del ejército, que se reunía los martes por la tarde, y al que era posible ingresar si se llevaba la recomendación adecuada.

Al poco tiempo, él y dos primos suyos fueron admitidos. Obtuvieron armas, chalecos antibalas, ametralladoras Ingram, gorros pasamontañas, silenciadores, entrenamiento en el manejo de explosivos y directrices de cómo y contra quién actuar. Ejército secreto anticomunista, Gremio Anticomunista Salvadoreño, Brigada Anticomunista Maximiliano Hernández Martínez, Comando Metropolitano, Escuadrón de la muerte, los squash". ${ }^{20}$

Desde el entusiasmo y convencimiento expresados en este pasaje en el que se vislumbra tanto génesis como apología del terrorismo de derechas, hasta la furia y el dolor producto de sentirse traicionado por los aliados dentro y fuera del país -respectivamente la oligarquía cafetalera y el gobierno de los Estados Unidos-, los cuatro capítulos introspectivos dedicados a la perspectiva de un miembro de los escuadrones de la muerte critican la hipocresía de quienes se sirvieron de sus servicios mientras fue conveniente para luego descartarlos debido a "una serie de inconvenientes relacionados con los derechos humanos" ${ }^{21}$ después de la firma de los acuerdos de paz, por un gobierno formado por "militares traidores y por comunistas disfrazados de demócratas cristianos" que "les había arrebatado el poder y los había abofeteado". ${ }^{22}$ Tanto en estas amargas consideraciones como en su respuesta al asesor norteamericano cuya misión consiste en hacerlo desistir de las acciones violentas - desde tráfico de drogas y armas, hasta secuestros, torturas y asesinatos- que aún siguen cometiendo los ex miembros de las fuerzas paramilitares, ${ }^{23}$ reverbera el tenor de la crítica articulada en la novela El arma en el hombre de Horacio Castellanos Moya al modo inconsecuente e intempestivo en que se llevó a cabo el desmantelamiento del aparato represivo a partir del año 1992 en El Salvador por medio del monólogo del personaje Robocop. ${ }^{24}$

20 Núñez Handal, 26. Cursivas en el original.

21 Ibid, 27.

22 Ibid, 68.

23 “¿Pero cómo vamos a pedirles otra cosa a estas gentes si es lo único que saben hacer?”. Ibid, 96.

24 Horacio Castellanos Moya, El arma en el hombre (Barcelona, España: Tusquests Editores, 2001). 
Por otro lado, en el transcurso de la novela, y gracias a diversas alusiones oblicuas, quien lee se da cuenta de que el miembro sin nombre de los escuadrones de la muerte no es otro que el tío de Natalia, quien, a su vez, comprueba que sus padres siempre habían estado al tanto de las actividades paramilitares de su pariente y -lo que para ella es aún más perturbador- están en total acuerdo con estas. ${ }^{25}$ Entender que sus padres no fueron tan solo víctimas-cómplices del mandato de no ver, ni oír, ni escuchar lo que sucedía a su alrededor por miedo a las represalias, sino que también apoyaron las acciones más violentas y extremas perpetradas en nombre de la defensa de la patria, por personas de su propia familia, como su tío, implica aceptar que la división ideológica y moral que tuvo lugar en el país atraviesa el espacio familiar, destruyendo la ilusión de un núcleo intacto, preservado de los efectos de la violencia política. A la inversa, las divisiones ideológicas en la familia refractan en el modo en que la comunidad nacional fue escindida por la guerra. Así, la indigación de las diferencias al interior del microcosmos familiar permite explorar las diversas perspectivas sobre lo ocurrido en esos años y sus efectos en la posguerra a nivel nacional.

Pero la división familiar es aún más profunda, pues Edgardo, primo de Natalia y nada menos que hijo del paramilitar, es uno de los tantos desaparecidos de la guerra. Por ende, el encarecido llamamiento al cese de la represión de Monseñor Romero en su homilía del 23 de marzo de 1980 -"Hermanos, son de nuestro mismo pueblo"-26 a quien Natalia escucha practicar en la sacristía poco antes de que comience, cobra en la novela un sentido aún más estrecho: la represión se dirige incluso a miembros de la misma familia, epítome si los hay del sentido profundo de una guerra civil. Dado que esta novela se centra en cómo la guerra desgarró el espacio de la vida privada, incluso de aquellos seres aferrados al percepticidio como forma de supervivencia, y su narrativa gira, específicamente, en torno de la percepción de Natalia cuando niña, un evento histórico clave como la última homilía de Monseñor Romero antes de su asesinato es narrada al pasar desde la comprensión sesgada por el desconocimiento que caracterizó su experiencia de la guerra. Solo como resultado de su trabajo de memoria, de sus investigaciones en el archivo e indagaciones en los recuerdos de sus amigos y familiares, Natalia accederá, finalmente, a una comprensión profunda, léase de la magnitud política e histórica, de este y otros hechos. Así, Dios tenía miedo ilumina cómo las atrocidades de la guerra fracturaron para siempre las identidades del pueblo salvadoreño en el día a día. Su terreno es la micro, no la macrohistoria. A este efecto, incluye diversas perspectivas de sobrevivientes de diversos extractos sociales y filiaciones políticas.

En la línea de las voces narrativas desde la perspectiva de las víctimas y sus familiares, Dios tenía miedo incluye un capítulo dedicado a Rosa María, la

25 Véase Núñez Handal, 136.

26 Ibid, 30. Cursivas en el original. 
La guerra salvadoreña vista desde la literatura autoficcional: Dios tenía miedo, de Vanessa Núñez Handal

madre de Edgardo, y otro dedicado a la niña Flor, una vecina de Natalia cuyo hijo fue asesinado durante la masacre de $1932 .{ }^{27}$ Asimismo, entre los diversos testimonios ficcionales contenidos, se encuentra el testimonio oral de un sobreviviente de 1932, en conversación con Natalia. ${ }^{28}$ Esta inclusión en la novela de la experiencia de un sobreviviente y de la madre de una víctima de la masacre del treinta y dos establece un vínculo entre las causas de la guerra civil desatada en 1980 y el levantamiento indígena de 1932, al mismo tiempo que sugiere la brutal masacre de dicho año como ominoso precedente del terrorismo de Estado de los años ochenta. En esta relación histórica de ambos sucesos resuena el poema "Todos" -1974- de Roque Dalton:

"Todos nacimos medio muertos en 1932

sobrevivimos pero medio vivos

cada uno con una cuenta de treinta mil muertos enteros

que se puso a engordar sus intereses

sus réditos

y que hoy alcanza para untar de muerte a los que siguen

naciendo

medio muertos

medio vivos". 29

Por ello, no sorprende que la novela contenga un capítulo en el que la narradora recuerda la muerte de un poeta asesinado por sus propios compañeros de lucha, acusado de ser un agente de la CIA -al igual que en el caso de la referencia a Monseñor Romero, se trata de una mención al sesgo, sin dar su nombre-. La reacción de Natalia, al enterarse de esta muerte, es pensar que "si la poesía no había bastado para salvar a aquel hombre, entonces no debía servir de nada." ${ }^{30}$ Sin embargo, en tanto intervención en la esfera pública como novela de la memoria, Dios tenía miedo demuestra una posible función si no de la poesía en sentido estricto, sí de la escritura literaria o poética, la cual coexiste con este reconocimiento de la narradora de la futilidad de la poesía, es decir, de las limitaciones de lo literario. Entiendo esta ambivalencia que subyace en la novela como el síntoma de una tensión dialéctica con respecto a la necesidad de una literatura, un lenguaje, podríamos decir, que exprese el sufrimiento de la guerra,

27 Véanse, respectivamente, los capítulos 59 y 29.

28 Véase el capítulo 44.

29 Roque Dalton, Las historias prohibidas del Pulgarcito (México, DF: Siglo XXI Editores, 1999, 12a ed.), 128.

30 Núñez Handal, 49. 
sin traicionar la irreductibilidad de dicho sufrimiento, por medio del consuelo o el placer estético. ${ }^{31}$

En lo que respecta a las estrategias literarias empleadas por la autora, la inclusión de testimonios ficticios en Dios tenía miedo, como el del torturador o el del sobreviviente de la masacre de 1932 anteriormente mencionados, va más allá del efecto dialógico que se desprende de las múltiples voces y perspectivas que conforman la novela: crea la ilusión de autenticidad de un testimonio coral al estilo del clásico La noche de Tlatelolco -1971- de Elena Poniatowska, al tiempo que -por tratarse justamente de testimonios inventados contenidos en una obra de ficción- sugiere que la verdad encerrada en ellos no depende de su carácter referencial propiamente dicho, ya que estos testimonios no existen más allá de la novela. Por el contrario, y desde un acercamiento constructivista a la noción de verdad, su validez dependerá de nuestra capacidad de interpretarlos según un punto de vista moralmente válido y de que los consideremos relevantes para explicar el trauma de la guerra. Una vez más, es evidente la compleja ambigüedad del texto.

Paralelamente, Vanessa Núñez Handal incluye fuentes documentales en su novela: desde eslóganes políticos hasta discursos radiales, pasando por artículos y anuncios periodísticos y graffiti. Estos intertextos también anclan la novela en el paradigma testimonial de La noche de Tlatelolco; pero, esta vez, en el sentido implicado por el paradigma documental, cuya verdad se sustenta en el archivo. Así, el trabajo de memoria de la novela, si bien apuesta por la invención como forma de acceder al pasado, no renuncia al archivo como soporte de la experiencia. En otras palabras, al abrir la narración en primera persona a una miríada de voces y perspectivas, remedando un testimonio coral, la autoficción de Dios tenía miedo juega tanto con las convenciones de la autobiografía y la novela autobiográfica, como con las de la novela testimonio. Dada la relevancia de la literatura testimonial en el contexto centroamericano, no debería sorprendernos que la práctica de la autoficción en Centroamérica incorpore el testimonio y la novela testimonio, más que la autobiografía, como escritura del yo con la cual dialogar, en busca de una forma de narrar que permita entender el trauma de la guerra. ${ }^{32}$ No hay en este gesto de la autora un reconocimiento del carácter autoficcional que el testimonio pueda tener a pesar de sí mismo, si pensamos por ejemplo en textos claves para el contexto centroamericano, como el testimonio de Rigoberta Menchú o Las cárceles clandestinas de El Salvador de Ana Guadalupe Martínez, los cuales no buscan identificarse con la escritura ficcional

31 Para una discusión teórica sobre posibilidades, limitaciones y responsabilidades de la representación literaria de hechos traumáticos, véase Thomas Trezise, "Unspeakable", The Yale Journal of Criticism (EE. UU.) 14, n. 1 (2001): 39-66, esp. 44-46.

32 La novela 300 (Heredia, Costa Rica: EUNA, 2011) de Rafael Cuevas Molina es otro ejemplo de una novela de la memoria, en este caso de la guerra en Guatemala, que recrea un testimonio coral por medio de su estructura narrativa. 
La guerra salvadoreña vista desde la literatura autoficcional: Dios tenía miedo, de Vanessa Núñez Handal

sino, más bien, todo lo contrario. ${ }^{33}$ En su lugar, hay una apuesta por romper con la dicotomía ficción-testimonio -o biografía-, y evadir, de este modo, las limitaciones de un paradigma referencial de la verdad, sin por eso renunciar a la documentación como una de las aristas de la construcción de la memoria, pero bajo el manto de la ficción.

\section{Palabras finales}

No obstante las múltiples voces, el lector puede seguir a Natalia, que sin duda se mantiene como la principal narradora y protagonista de la novela, a lo largo de un relato de memoria por medio del cual lleva a cabo el pasaje de la infancia a la adultez, como en una novela de aprendizaje o Bildungsroman. Desde su ingenua perspectiva de niña hasta su inquisitiva mirada retrospectiva del 2009, Natalia sufre una profunda transformación, producto de sus indagaciones en el pasado por medio de entrevistas a diversas personas, las mencionadas conversaciones con su amiga Jimena, las constantes preguntas a sus padres y la lectura minuciosa de los periódicos y otras publicaciones de la época en la biblioteca de la UCA. Atreverse a romper el silencio, haciendo preguntar incómodas, informándose de todas las maneras posibles sobre lo ocurrido durante la guerra, será el ritual de iniciación que marque la pérdida definitiva de la inocencia y la entrada en la vida adulta de Natalia, pero esto solo será posible como consecuencia del reconocimiento de la propia responsabilidad en el percepctidio:

"Entonces, como quien despierta de un letargo, comprendí que yo también había vivido de espaldas y había llenado mi mundo de aquello que no pudiera dañarme. Pero los muertos, que ahora me hablaban, reclamaban mi desdén y mi indiferencia ante sus suplicios. Comprendí que yo, con mi silencio, también había sido cómplice de esta historia macabra de muerte y dolor" 34

33 Rigoberta Menchú y Elizabeth Burgos, Me llamo Rigoberta Menchú y así me nació la conciencia (México, D.F.: Siglo XXI Editores, 1985). Las cárceles clandestinas de El Salvador: Libertad por el secuestro de un oligarca fue circulado en forma de panfleto en 1978; la primera edición en forma de libro es de 1980 por la Universidad Autónoma de Sinaloa. Valga la pena aclarar que la vocación referencial del testimonio, su promesa de autenticidad y representatividad han sido motivo de múltiples debates y controversias. Para un detallado señalamiento del carácter profundamente literario y construido del testimonio en Centroamérica en particular, véase Werner Mackenbach, "Realidad y ficción en el testimonio centroamericano", Istmo. Revista virtual de estudios literarios y culturales centroamericanos, 2 (2001): http://istmo.denison.edu/ n02/articulos/realidad.html. Para un estudio que abarque toda Hispanoamérica, véase Elzbieta Sklodovska, Testimonio hispanoamericano: Historia, teoría, poética (Frankfurt am Main, Alemania: Peter Lang, 1992). Para un panorama de las coincidencias entre el testimonio y la autoficción en lo que respecta a la hibridez de su pacto de lectura y, sobre todo, su lugar de enunciación, véase Julia Negrete, 234-235.

34 Núñez Handal, 132. 
El trabajo de memoria, que se desprende de este reconocimiento como un mandato, la lleva no solo a confrontar a sus padres, sino también a quien lea su obra:

“¿Recuerdas aún? ¿O has decidido olvidar, como la mayoría, esta guerra cuyos muertos todavía cantan por las noches y aman las causas por las que murieron? [...] ¿No los oyes? Es porque el olvido, no la muerte, ha comenzado a silenciarlos" ${ }^{35}$

El llamado a escuchar, a ver e indagar, a romper el silencio impuesto por el percepctidio como instrumento del miedo desborda, así, los límites de la novela. El pacto ambiguo de la autoficción le permite a Natalia/Vanessa hacerse y hacernos preguntas que no pueden ser clausuradas como meras ficciones al tiempo que su estatuto novelesco ofrece resguardo de un miedo que no cesa y otro espacio desde el que acercarse a la verdad. 